\title{
Fos Protein Expression and Cocaine-Seeking Behavior in Rats after Exposure to a Cocaine Self-Administration Environment
}

\author{
Janet L. Neisewander, ${ }^{1}$ David A. Baker, ${ }^{1}$ Rita A. Fuchs, ${ }^{1}$ Ly T. L. Tran-Nguyen, ${ }^{1}$ Art Palmer, ${ }^{1}$ and \\ John F. Marshall2 \\ 1Department of Psychology, Arizona State University, Tempe, Arizona 85287-1104, and 2Department of Psychobiology, \\ University of California, Irvine, California 92697-4550
}

To examine neuronal activation associated with incentive motivation for cocaine, cocaine-seeking behavior (operant responding without cocaine reinforcement) and Fos expression were examined in rats exposed to saline and cocaine priming injections and/or a self-administration environment. Rats were first trained to self-administer cocaine or received yoked saline administration ("control"). They then received 21 daily exposures to either the self-administration environment ("extinction") or a different environment ("no extinction") without cocaine available. Extinction training, used to decrease incentive motivation for cocaine elicited by the self-administration environment, decreased cocaine-seeking behavior elicited by both the environment and the cocaine priming injection. Exposure to the self-administration environment enhanced Fos expression in the no extinction group relative to control and extinction groups in the anterior cingulate, basolateral amygdala, hippocampal CA1 region, dentate gyrus, nucleus accumbens shell and core, and central gray area, regardless of whether or not priming injections were given. The priming injections enhanced
Fos expression in the ventral tegmental area, caudate putamen, substantia nigra pars reticulata, entorhinal cortex, central amygdala, lateral amygdala, arcuate nucleus, and central gray area, regardless of group. Thus, these changes likely reflect an unconditioned effect from either cocaine or injection stress. The priming injections also enhanced Fos expression in the anterior cingulate, but only in cocaine-experienced groups, suggesting that this enhancement reflects an experience-dependent motivational effect of the priming injections. The results suggest that different neural circuits may be involved in the incentive motivational effects of cocaine-paired environmental stimuli versus priming injections and that the anterior cingulate may be part of a common pathway for both.

Key words: cocaine; cocaine-seeking behavior; incentive motivation; self-administration; reinstatement; priming injections; cocaine conditioning; cocaine-paired stimuli; limbic system; basal ganglia; amygdala; anterior cingulate; Fos protein expression; neuronal activation; immediate early genes
Cocaine and cocaine-paired environmental stimuli produce incentive motivational effects that are thought to contribute to craving and relapse (Stewart, 1983). This phenomenon can be studied in animals using the extinction-reinstatement model (Stewart, 1983; Markou et al., 1993; Fuchs et al., 1998). In this model, animals are first trained to press a lever for cocaine reinforcement. Subsequently, they are tested for cocaine-seeking behavior (i.e., lever pressing without cocaine reinforcement) elicited by environmental stimuli or priming injections of cocaine.

Theories suggest that incentive motivational effects of cocaine and cocaine-paired stimuli involve the same neural pathways (Stewart, 1983; Robinson and Berridge, 1993); however, recent studies suggest this may not be the case. First, the ability of cocaine-paired stimuli to reinstate cocaine-seeking behavior or to serve as cocaine-conditioned secondary reinforcers is disrupted by lesions of the basolateral amygdala $(\mathrm{BlA})$, whereas these lesions fail to alter cocaine self-administration (Whitelaw et al., 1996; Meil and See, 1997). These findings suggest that the BlA is

\footnotetext{
Received June 23, 1999; revised Oct. 4, 1999; accepted Oct. 28, 1999.

This work was supported by National Institute on Drug Abuse Grants DA11064 (J.L.N.), DA05816 (L.T.L.T.), and DA10249 (J.F.M.). We thank Ron McPherson for his expert technical assistance and Dr. Miles Orchinik for the use of his image analysis system.

Correspondence should be addressed to Dr. Janet Neisewander, Department of Psychology, Arizona State University, P.O. Box 871104, Tempe, AZ 85287-1104. E-mail: janet.neisewander@asu.edu.

Copyright (C) 2000 Society for Neuroscience $\quad 0270-6474 / 00 / 200798-08 \$ 15.00 / 0$
}

involved in cocaine-seeking behavior elicited by cocaine-paired stimuli but not cocaine itself. Second, it is unclear whether dopamine plays a similar role in cocaine-seeking behavior elicited by cocaine versus cocaine-paired stimuli. Reinstatement of cocaineseeking behavior by cocaine priming injections is mimicked by administration of dopamine agonists and attenuated by dopamine antagonists (Self et al., 1996; Weissenborn et al., 1996). The latter suggests that dopamine neurotransmission is necessary for cocaine-reinstated cocaine-seeking behavior. Furthermore, cocaine-seeking behavior is reinstated by morphine inf usions into the ventral tegmental area (VTA) which, similar to cocaine priming injections, enhance dopamine neurotransmission in the nucleus accumbens (NAc) (Stewart, 1984). Also, changes in cocainereinstated cocaine-seeking behavior during the course of withdrawal from a self-administration regimen correspond to changes in extracellular dopamine in the amygdala (Tran-Nguyen et al., 1998). However, cocaine-seeking behavior elicited by cocaine-paired environmental stimuli is sometimes (Gratton and Wise, 1994; Kiyatkin and Stein, 1994; Di Ciano et al., 1998), but not always (Neisewander et al., 1996; Bradberry and Rubino, 1998; Tran-Nguyen et al., 1998), accompanied by an increase in extracellular dopamine in mesolimbic terminals. Thus, enhanced extracellular dopamine in these regions may not be necessary for cocaine-seeking behavior elicited by cocaine-paired stimuli.

Studies thus far have used techniques that are limited to examining a specific region. The purpose of the present study was to 
identify other brain regions that may be involved in cocaineseeking behavior using Fos protein expression as a marker for neuronal activation (Sharp et al., 1993; Herrera and Robertson, 1996). Fos is the product of $c$-fos, an immediate early gene transiently induced by various stimuli, including cocaine (Graybiel et al., 1990; Young et al., 1991) and cocaine-associated stimuli (Brown et al., 1992; Crawford et al., 1995). Because Fos is a transcription factor, it may play a role in long-lasting neuronal changes involved in incentive motivational learning. Thus, the present study examined the effects of exposure to a cocaine self-administration environment on cocaine-seeking behavior and Fos protein expression in various limbic and motor brain regions. In addition, this study examined whether these effects were further enhanced by saline and cocaine priming injections.

\section{MATERIALS AND METHODS}

Animals and surgery. Male Sprague Dawley rats, weighing 250-300 gm at the start of the experiment, were housed individually in a temperaturecontrolled colony room with a $12 \mathrm{hr}$ reverse light/dark cycle (lights off at 6:00 A.M.). The housing conditions and care of the animals were consistent with those specified in the Guide for the Care and Use of Laboratory Animals (Institute of Laboratory Animal Resources on Life Science, National Research Council, 1996). Animals were acclimated to handling for at least $5 \mathrm{~d}$ before surgical implantation of intravenous catheters. Catheters were constructed from SILASTIC tubing $(10 \mathrm{~cm}$; inner diameter $0.012 \times$ outer diameter 0.025 inches; Dow Corning, Midland, MI) connected to a bent 22 gauge metal cannula encased within a plastic screw connector (Plastics One, Roanoke, VA) at one end and affixed with a small ball of aquarium sealant $\sim 4 \mathrm{~cm}$ from the other end. Before surgery, the animals received atropine sulfate $(10 \mathrm{mg} / \mathrm{kg}$, i.p.; Sigma, St. Louis, MO) to decrease bronchial secretions. Ten minutes later, the animals were anesthetized with sodium pentobarbital $(50 \mathrm{mg} / \mathrm{kg}$, i.p.; Sigma). Incisions were made in clean shaven areas on the neck to expose the jugular vein and on the head to expose the skull. A burrow was then made subcutaneously from the incision on the neck to the incision on the head, and the catheter was pulled through the burrow. A small incision was made in the jugular vein, and the catheter was inserted into the vein until flush with the ball of aquarium sealant. The catheter was then secured to the vein with sutures on both sides of the ball. The metal end of the catheter was secured to the skull using dental acrylic cement and small anchor screws drilled into the skull. The incisions were then sutured and treated with a topical antibiotic. Throughout the experiment, the catheters were flushed daily with a solution of $0.1 \mathrm{ml}$ of bacteriostatic saline containing heparin sodium $(10 \mathrm{U} / \mathrm{ml}$; Elkins-Sinn, Cherry Hill, NJ), streptokinase $(0.67 \mathrm{mg} / \mathrm{ml}$; Astra Pharmaceutical Products, Westerborough, MA), and ticarcillin disodium $(66.67 \mathrm{mg} / \mathrm{ml}$; SmithKline Beecham Pharmaceuticals, West Chester, PA) to maintain patency. Catheter patency was verified periodically throughout the experiment by administering $0.8 \mathrm{mg}$ of methohexital sodium (Eli Lilly \& Co., Indianapolis, IN), a dose that anesthetizes the animals briefly only when administered intravenously.

Self-administration training. Cocaine self-administration training began $5 \mathrm{~d}$ after surgery and took place during the animals' dark cycle. Animals were randomly assigned to groups that received either responsecontingent cocaine administration or an equal volume of saline contingent upon schedule completions made by an animal in the cocaine group. During the initial phase of training, animals in the cocaine group were placed on a fixed ratio (FR) 1 schedule of cocaine reinforcement $(0.5$ $\mathrm{mg} / \mathrm{kg}$ per $0.1 \mathrm{ml}$, i.v.) until they received at least 10 cocaine inf usions in $1 \mathrm{hr}$. Session length during this phase varied between 2 and $6 \mathrm{hr}$ depending on the animals' performance. After reaching the criterion of $10 \mathrm{inf}$ usions/hr, the animals received 15 daily $2 \mathrm{hr}$ sessions during which the schedule of reinforcement was increased every $5 \mathrm{~d}$ from an FR 1 to a variable ratio (VR) 2, and then to a VR 5.

Training sessions took place in operant chambers that were housed within ventilated sound-attenuating chambers. The operant chambers were equipped with a lever, a cue light located $4 \mathrm{~cm}$ above the lever, a tone generator $(500 \mathrm{~Hz}, 10 \mathrm{~dB}$ above background), and a house light located in the center of the back (Med Associates, St. Albans, VT). The infusion pumps were connected via Tygon tubing to liquid swivels (Instech, Plymouth Meeting, PA) above the chamber. The swivels were connected to the screw cap of the catheter via Tygon tubing that ran through a metal spring leash. Schedule completions by a cocaine animal resulted in simultaneous activation of the house light, cue light, and tone generator, followed $1 \mathrm{sec}$ later by activation of the infusion pump. The inf usion was delivered over a $6 \mathrm{sec}$ period, after which the stimulus light, tone, and pump were inactivated simultaneously. The house light remained activated for a $20 \mathrm{sec}$ timeout period. Saline-yoked controls received presentation of the same stimulus complex contingent upon schedule completions by an animal in the cocaine group, except that saline was infused rather than cocaine. Responses by saline-yoked controls had no scheduled consequences. No priming infusions were given during training. To facilitate acquisition of cocaine self-administration (Carroll et al., 1981; de la Garza and Johanson, 1987), access to food was restricted to $1 \mathrm{hr} / \mathrm{d}$ until the rats received at least 10 inf usions per day for 3 consecutive days. All animals reached this criterion within $8 \mathrm{~d}$ of training and were then given food ad libitum throughout the remainder of the experiment, including the test day.

Extinction training. During self-administration training, an association is presumably formed between the environmental stimuli and the unconditioned effects of cocaine, such that exposure to the environmental stimuli alone can elicit incentive motivation for cocaine. Extensive extinction training, which refers to repeated presentation of the cocainepaired environmental stimuli in the absence of cocaine reinforcement, has been shown to decrease incentive salience of cocaine-paired stimuli as reflected by a decrease in stimuli-elicited self-reports of craving in humans (Childress et al., 1988) and drug-seeking behavior in animals (Meil and See, 1997). Thus, to manipulate incentive salience of the cocaine-paired environmental stimuli in this study, animals were further assigned to groups that either did or did not receive extinction training. Assignment to these groups was counterbalanced for number of cocaine inf usions received during self-administration training. Extinction training began the day after self-administration training was completed and consisted of $2 \mathrm{hr}$ exposures to the self-administration environment across 21 consecutive days. The stimulus complex paired previously with cocaine infusions was presented once every 5 min during the entire $2 \mathrm{hr}$ period. Animals that did not receive extinction training were transported to a room different from the self-administration room and were placed into Plexiglas holding cages. The holding cages were the same size as the operant chambers, but the bedding and visual cues around the cages were different from that of the operant chambers. Saline-yoked controls received the same training as their paired experimental animal. All animals were connected to a liquid swivel while they were confined to their respective environments; however, the swivels were not connected to a pump and no infusions were delivered.

Test for cocaine-seeking behavior. The day after extinction training was completed, all animals were reintroduced to the self-administration chambers and were tested for cocaine-seeking behavior, defined as lever presses in the absence of cocaine reinforcement. Animals within each group were randomly assigned to groups tested for cocaine-seeking behavior and Fos protein expression after exposure to the self-administration environment only or after exposure to the self-administration environment and priming injections. To examine whether changes in Fos protein expression were caused by the act of lever pressing, an additional cocaine group was included that did not receive extinction training and was exposed to the self-administration environment but without levers present. Thus, the design of this experiment yielded seven groups $(n=$ 5-7), as shown in Table 1.

Testing began by placing the animals into the operant chambers for a 90 min extinction test phase. Animals that were tested after exposure to the self-administration environment only were then removed from the chambers and killed within $30 \mathrm{~min}$, with the exception of one animal in the "no extinction" group that was killed 90 min after testing. The remaining animals received an injection of saline $(1 \mathrm{ml} / \mathrm{kg}$, i.p.) to examine the effects of an injection on reinstatement of cocaine-seeking behavior. One hour later, the animals received an injection of cocaine hydrochloride $(15 \mathrm{mg} / \mathrm{kg}$, i.p.) to examine the effects of a cocaine priming injection on reinstatement of cocaine-seeking behavior. Ninety minutes later, the animals were removed from the chambers and killed within 30 min. Every 5 min throughout testing, the stimulus complex paired previously with infusions was presented, except that the infusion pump was disconnected from the swivel. The noncontingent presentation of the stimulus complex was used to model craving and relapse that occurs in humans after inadvertent exposure to cocaine-paired stimuli. Responses on the levers were recorded but had no scheduled consequences.

Fos protein immunoreactivity. After behavioral testing, animals were deeply anesthetized using sodium pentobarbital $(50 \mathrm{mg} / \mathrm{kg}$, i.p.) and 
Environment only

\begin{tabular}{|c|c|c|c|c|c|c|c|}
\hline \multirow[b]{2}{*}{ Brain region } & \multicolumn{4}{|c|}{ Environment only } & \multicolumn{3}{|c|}{ Environment and priming injections } \\
\hline & $\begin{array}{l}\text { Controls } \\
(n=5)\end{array}$ & $\begin{array}{l}\text { Extinction } \\
(n=7)\end{array}$ & $\begin{array}{l}\text { No extinction } \\
(n=5)\end{array}$ & $\begin{array}{l}\text { No extinction- } \\
\text { no lever } \\
(n=6)\end{array}$ & $\begin{array}{l}\text { Controls } \\
(n=6)\end{array}$ & $\begin{array}{l}\text { Extinction } \\
(n=6)\end{array}$ & $\begin{array}{l}\text { No extinction } \\
(n=6)\end{array}$ \\
\hline Nucleus accumbens - core & $20.60 \pm 4.31$ & $18.11 \pm 4.22$ & $33.25 \pm 2.99$ & $28.96 \pm 5.70$ & $21.14 \pm 5.46$ & $30.70 \pm 8.76$ & $42.39 \pm 6.21$ \\
\hline - shell & $19.36 \pm 5.49$ & $20.28 \pm 4.68$ & $27.13 \pm 5.78$ & $35.30 \pm 7.85$ & $13.27 \pm 3.22$ & $19.24 \pm 4.83$ & $35.53 \pm 7.49$ \\
\hline Ventral pallidum & $9.42 \pm 2.12$ & $13.99 \pm 4.71$ & $13.85 \pm 4.37$ & $7.30 \pm 1.84$ & $8.29 \pm 3.18$ & $17.32 \pm 1.95$ & $18.71 \pm 2.56$ \\
\hline Ventral tegmental area & $3.56 \pm 1.59$ & $5.24 \pm 1.50$ & $12.62 \pm 6.12$ & $10.02 \pm 2.66$ & $19.32 \pm 6.97$ & $13.66 \pm 1.13$ & $17.70 \pm 4.22$ \\
\hline Dorsal caudate putamen & $9.68 \pm 4.76$ & $2.71 \pm 0.96$ & $16.59 \pm 5.97$ & $14.18 \pm 4.15$ & $17.53 \pm 7.07$ & $25.96 \pm 4.89$ & $31.52 \pm 5.84$ \\
\hline Substantia nigra - compacta & $5.76 \pm 2.00$ & $8.08 \pm 2.81$ & $8.54 \pm 2.46$ & $7.63 \pm 1.86$ & $8.89 \pm 2.35$ & $9.29 \pm 2.04$ & $13.42 \pm 3.10$ \\
\hline - reticulata & $2.47 \pm 0.84$ & $7.03 \pm 2.72$ & $8.28 \pm 1.95$ & $6.26 \pm 1.66$ & $13.18 \pm 2.90$ & $23.11 \pm 5.00$ & $27.61 \pm 3.30$ \\
\hline Cortex - motor & $23.71 \pm 6.80$ & $15.08 \pm 4.98$ & $32.44 \pm 8.03$ & $30.51 \pm 5.04$ & $23.14 \pm 5.03$ & $29.13 \pm 5.48$ & $38.58 \pm 5.46$ \\
\hline - anterior cingulate & $20.42 \pm 4.31$ & $19.25 \pm 6.28$ & $40.49 \pm 8.32$ & $38.68 \pm 9.72$ & $20.34 \pm 6.23$ & $41.89 \pm 5.99$ & $41.12 \pm 8.25$ \\
\hline - entorhinal & $10.33 \pm 1.82$ & $12.28 \pm 2.32$ & $14.24 \pm 1.45$ & $17.31 \pm 1.23$ & $15.63 \pm 3.29$ & $20.54 \pm 3.02$ & $18.36 \pm 2.01$ \\
\hline Amygdala - basolateral & $4.92 \pm 1.76$ & $5.67 \pm 1.34$ & $12.99 \pm 5.03$ & $11.02 \pm 1.38$ & $8.41 \pm 1.60$ & $10.29 \pm 1.90$ & $15.43 \pm 1.90$ \\
\hline - medial & $12.28 \pm 3.43$ & $10.58 \pm 2.26$ & $16.06 \pm 6.15$ & $20.16 \pm 4.42$ & $10.83 \pm 2.22$ & $9.23 \pm 2.29$ & $20.06 \pm 5.16$ \\
\hline - central & $9.12 \pm 2.15$ & $13.67 \pm 3.42$ & $11.21 \pm 3.19$ & $11.52 \pm 2.26$ & $39.86 \pm 9.77$ & $40.13 \pm 8.84$ & $44.91 \pm 8.75$ \\
\hline - lateral & $0.55 \pm 0.23$ & $0.85 \pm 0.23$ & $1.17 \pm 0.38$ & $1.57 \pm 0.31$ & $2.99 \pm 1.25$ & $3.27 \pm 0.55$ & $5.03 \pm 1.53$ \\
\hline - cortical & $4.22 \pm 2.25$ & $1.36 \pm 0.28$ & $4.58 \pm 0.96$ & $8.06 \pm 3.40$ & $2.55 \pm 0.94$ & $2.65 \pm 0.67$ & $4.00 \pm 1.49$ \\
\hline Hippocampal - CA1 region & $8.98 \pm 1.87$ & $9.73 \pm 1.88$ & $11.23 \pm 0.61$ & $14.79 \pm 2.56$ & $7.84 \pm 1.50$ & $7.93 \pm 1.39$ & $14.43 \pm 2.90$ \\
\hline - CA3 region & $3.60 \pm 1.45$ & $5.47 \pm 2.65$ & $5.16 \pm 0.90$ & $4.18 \pm 0.97$ & $3.69 \pm 1.00$ & $3.51 \pm 0.91$ & $4.40 \pm 0.50$ \\
\hline - dentate gyrus & $5.10 \pm 1.49$ & $4.95 \pm 1.15$ & $6.34 \pm 0.37$ & $7.36 \pm 1.38$ & $3.37 \pm 0.51$ & $3.34 \pm 0.78$ & $6.08 \pm 0.52$ \\
\hline - v. subiculum & $21.95 \pm 4.26$ & $17.48 \pm 2.35$ & $26.81 \pm 3.64$ & $31.07 \pm 3.95$ & $17.11 \pm 1.74$ & $17.07 \pm 3.35$ & $27.37 \pm 7.26$ \\
\hline Lateral septal area & $17.64 \pm 5.95$ & $13.17 \pm 5.11$ & $13.87 \pm 4.71$ & $13.83 \pm 3.62$ & $7.35 \pm 1.98$ & $6.92 \pm 2.00$ & $16.44 \pm 3.44$ \\
\hline Lateral hypothalamus & $13.45 \pm 1.83$ & $12.21 \pm 1.67$ & $15.81 \pm 6.49$ & $16.56 \pm 3.06$ & $17.62 \pm 2.59$ & $16.35 \pm 1.95$ & $21.11 \pm 3.67$ \\
\hline Arcuate nucleus & $17.46 \pm 3.57$ & $21.12 \pm 2.80$ & $24.87 \pm 4.28$ & $36.13 \pm 4.46$ & $23.79 \pm 3.33$ & $38.33 \pm 6.20$ & $35.79 \pm 9.07$ \\
\hline Central gray area & $10.04 \pm 2.50$ & $10.42 \pm 1.14$ & $17.05 \pm 3.45$ & $13.57 \pm 3.02$ & $18.95 \pm 2.02$ & $16.37 \pm 1.39$ & $17.24 \pm 1.43$ \\
\hline
\end{tabular}

transcardially perfused with ice-cold $0.1 \mathrm{M}$ PBS, $\mathrm{pH} 7.4$, followed by ice-cold $4 \%$ paraformaldehyde in $0.1 \mathrm{M} \mathrm{PBS,} \mathrm{pH} \mathrm{7.4.} \mathrm{The} \mathrm{brains} \mathrm{were}$ removed, post-fixed for $60 \mathrm{~min}$, and then stored in $30 \%$ sucrose at $4^{\circ} \mathrm{C}$. Coronal sections $(40 \mu \mathrm{m})$ were collected at levels corresponding to 1.6, $-0.26,-2.56$, and $-5.6 \mathrm{~mm}$ from bregma (Paxinos and Watson, 1986) using a freezing microtome. All of the tissue sections used in this experiment were processed for Fos protein expression at the same time. The tissue was rinsed in $0.1 \mathrm{M}$ PBS (three times for $10 \mathrm{~min}$ each) and incubated in 0.1 M PBS containing 5\% normal goat serum (NGS) (Vector Laboratories, Burlingame, CA) and 0.2\% Triton X-100 (Sigma) for $1 \mathrm{hr}$. Sections were then incubated for $48 \mathrm{hr}$ at $4^{\circ} \mathrm{C}$ in $0.1 \mathrm{M}$ PBS containing anti-Fos rabbit polyclonal antibody (1:20,000; Oncogene Science, Cambridge, MA) and $0.1 \%$ Triton X-100. The sections were then rinsed in 0.1 M PBS (six times for $5 \mathrm{~min}$ each) and incubated in $0.1 \mathrm{M}$ PBS containing biotinylated goat anti-rabbit $\operatorname{IgG}$ (1:200; Vector Laboratories) and 1\% NGS for $1 \mathrm{hr}$. The sections were rinsed again using $0.1 \mathrm{M}$ PBS (three times for $10 \mathrm{~min}$ each) and incubated with avidin-biotinylated peroxidase complex (ABC Elite kit; Vector Laboratories) for $1 \mathrm{hr}$. The reaction was terminated by rinsing the tissue first in $0.1 \mathrm{M}$ PBS (two times for $10 \mathrm{~min}$ each) and then in stable peroxide substrate buffer $(10 \mathrm{~min}$; Pierce, Rockford, IL). The tissue was then incubated in metal-enhanced 3,3'diaminobenzidine tetrahydrochloride (Pierce) for 3-6 min. This reaction was terminated by rinsing the tissue in $0.1 \mathrm{M}$ PBS (two times for $10 \mathrm{~min}$ each) and then $0.1 \mathrm{M}$ Tris buffer $(10 \mathrm{~min})$. Sections were then mounted onto gelatin-coated slides, dried, and dehydrated before coverslipping. Fos immunoreactivity was quantified using an Olympus Opticals (Tokyo, Japan) microscope ( $40 \times$ magnification) attached to an image analysis system (Imaging Research Inc., St. Catherines, Ontario, Canada). The shape of the sampling area (rectangular or oval) was varied to best conform to the structure being measured with the sampling area ranging between $0.05-0.135 \mathrm{~mm}^{2}$ (see Fig. 3 caption for specific area used for each region). Objects within the sampling area of a neuronal region that met size and optical density criteria set by an observer blind to group assignments were counted as Fos-positive nuclei.

Statistical analyses. To examine the effect of extinction training on cocaine-seeking behavior, a repeated measures ANOVA of lever presses was conducted with self-administration history as a between subjects factor and extinction training day as a repeated measure. In addition, lever presses during extinction on the test day were analyzed using a $2 \times$ 2 factorial ANOVA with self-administration history and extinction training as between subjects factors. There were no significant differences between saline-yoked controls that received exposure to the operant chambers during extinction training versus those that were placed into the alternate environment on any of the dependent measures. Thus, the data from these groups have been combined to comprise a single salineyoked control group. To examine the effects of the saline and cocaine priming injections on lever presses, a repeated measures ANOVA was performed with conditioning group (i.e., "controls," "extinction," and "no extinction") as a between subjects factor and 30 min interval as a repeated measure. To examine the effects of exposure to the environment and the priming injections on Fos protein expression (i.e., Fospositive nuclei/0.1 $\mathrm{mm}^{2}$ ) a $3 \times 2$ factorial ANOVA was performed for each region with conditioning group (i.e., controls, extinction, and no extinction) and type of stimuli exposure (i.e., exposure to the environment only vs exposure to the environment and priming injections) as between subjects factors. In the anterior cingulate and central gray area, the analyses indicated trends $(p<0.166)$ toward an interaction that may have been obscured by low power and strong main effects. Thus, to further investigate possible group differences in these regions, a one-way ANOVA was performed with each group as a level. Significant effects were further analyzed using Fisher's LSD tests. To examine the influence of lever pressing on Fos protein expression in regions exhibiting a conditioning group effect, planned $t$ tests were performed comparing the no extinction-no lever group with the extinction and no extinction groups.

\section{RESULTS}

\section{Acquisition of cocaine self-administration}

The number of self-administration training sessions varied from 16 to 28 depending on the animals' performance during the initial training phase. The mean \pm SEM total amount of cocaine intake was $251.5 \pm 14 \mathrm{mg} / \mathrm{kg}$. The rats exhibited stable self-administration 


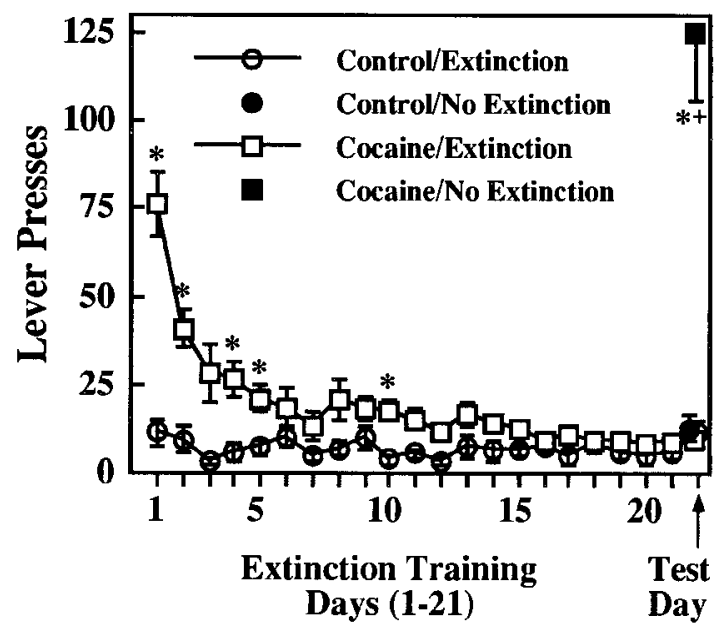

Figure 1. Effect of extinction training on cocaine-seeking behavior. Cocaine-seeking behavior is illustrated as nonreinforced lever presses ( \pm SEM) during the first 90 min on extinction training days and on the test day. ${ }^{*} p<0.05$, represents a difference from other groups tested; Fisher's LSD test. $+p<0.05$, represents a difference from the cocaine-extinction group tested on day $1 ; t$ test.

rates during the last $15 \mathrm{~d}$ of self-administration training that varied by $<10 \%$ with a mean \pm SEM daily intake of $13.9 \pm 0.85 \mathrm{mg} / \mathrm{kg}$.

\section{Cocaine-seeking behavior}

Extinction training abolished cocaine-seeking behavior (Fig. 1). The repeated measures ANOVA indicated a significant group by time interaction $\left(F_{(1,340)}=8.78 ; p<0.0001\right)$. Animals with a history of cocaine self-administration exhibited significantly more lever presses than controls on days $1,2,4,5$, and 10 of extinction training (Fisher's LSD test; $p<0.05$ ). Thus, cocaine-seeking behavior extinguished within $10 \mathrm{~d}$ of training because there were no significant differences between the groups on days 11-21. Furthermore, the ANOVA of lever presses on the test day indicated a significant cocaine history by extinction training interaction $\left(F_{(1,33)}=18.23 ; p<0.001\right)$. The cocaine-no extinction group exhibited significantly more lever presses than all other groups (Fisher's LSD test; $p<0.001$ ), and there were no differences among the other three groups.

Cocaine-seeking behavior was more robust after a $21 \mathrm{~d}$ withdrawal period relative to a $1 \mathrm{~d}$ withdrawal period (Fig. 1), consistent with previous research (Tran-Nguyen et al., 1998). Animals with a history of cocaine self-administration tested for the first time after a $21 \mathrm{~d}$ withdrawal period exhibited significantly more lever presses than animals tested after a $1 \mathrm{~d}$ withdrawal period, $\left(t_{(23)}=2.42 ; p<0.05\right)$.

The cocaine priming injection reinstated extinguished cocaineseeking behavior, and extinction training attenuated the effectiveness of the priming injection on reinstatement. Figure 2 illustrates cocaine-seeking behavior across all three test phases in animals that received the priming injections. An ANOVA of lever presses during the extinction test phase indicated a significant main effect of conditioning group $\left(F_{(2,15)}=20.6 ; p<0.0001\right)$. The no extinction group was significantly different from both the control and extinction groups (Fisher's LSD test; $p<0.001$ ). The saline primer did not alter lever presses in any of the groups. In contrast, the cocaine priming injection reinstated cocaineseeking behavior in all groups, although the effect was most robust in the no extinction group. A repeated measures ANOVA of lever presses during the 30 min intervals before and after the

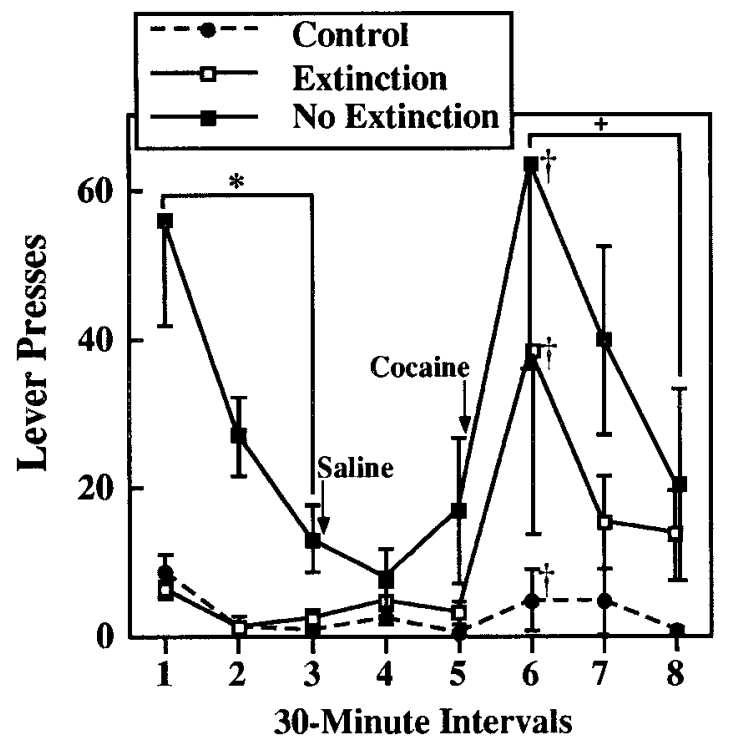

Figure 2. Effect of saline and cocaine priming injections on reinstatement of cocaine-seeking behavior in animals tested in all three phases. Cocaine-seeking behavior is illustrated as nonreinforced lever presses $\left( \pm\right.$ SEM) across 30 min intervals. ${ }^{*} p<0.05$, represents a difference from all other groups; Fisher's LSD test. $+p<0.05$, represents a difference from controls; Fisher's LSD test. $\dagger p<0.05$, represents a difference from previous $30 \mathrm{~min}$ interval; ANOVA main effect.

cocaine priming injection indicated a significant main effect of time $\left(F_{(1,15)}=7.6 ; p<0.05\right)$, suggesting that the cocaine primer increased lever presses regardless of conditioning group. However, planned comparisons of individual conditioning groups indicated that only the no extinction group exhibited a significant increase in lever presses during the $30 \mathrm{~min}$ interval after the cocaine priming injection relative to the $30 \mathrm{~min}$ interval preceding the injection, $\left(t_{(5)}=2.47 ; p<0.05\right)$. Furthermore, an ANOVA of lever presses during the 30 min intervals after the cocaine priming injection indicated a significant main effect of conditioning group $\left(F_{(2,15)}=4.0 ; p<0.05\right)$. Post hoc comparisons indicated that the no extinction group was significantly different from the control group (Fisher's LSD test; $p<0.05$ ) but not different from the extinction group.

\section{Fos protein immunoreactivity}

Figure 3 illustrates the regions analyzed, and Table 1 summarizes the results for each group in each region. The priming injections enhanced Fos protein expression (Fig. 4), evident as a main effect in the VTA $\left(F_{(1,29)}=8.11 ; p<0.01\right)$, dorsal caudate putamen $\left(F_{(1,29)}=13.25 ; p<0.001\right)$, substantia nigra pars reticulata $(\mathrm{SNr})$ $\left(F_{(1,29)}=34.13 ; p<0.001\right)$, entorhinal cortex $\left(F_{(1,29)}=8.64 ; p<\right.$ $0.01)$, central amygdala $\left(F_{(1,29)}=27.72 ; p<0.001\right)$, lateral amygdala $\left(F_{(1,29)}=15.98 ; p<0.001\right)$, arcuate nucleus $\left(F_{(1,29)}=7.01\right.$; $p<0.05)$, and central gray area $\left(F_{(1,29)}=9.33 ; p<0.005\right)$. In all of these regions, the priming injections enhanced Fos protein expression, regardless of conditioning group.

In the substantia nigra pars reticulata, there was also enhanced Fos protein expression attributable to previous cocaine experience and/or withdrawal (Fig. 5). There was a main effect of conditioning group in this region $\left(F_{(2,29)}=5.00 ; p<0.05\right)$, and post hoc comparisons indicated that both the extinction and no extinction groups exhibited a significant increase in Fos-positive nuclei relative to the control group (Fisher's LSD test; $p<0.05$ ), 


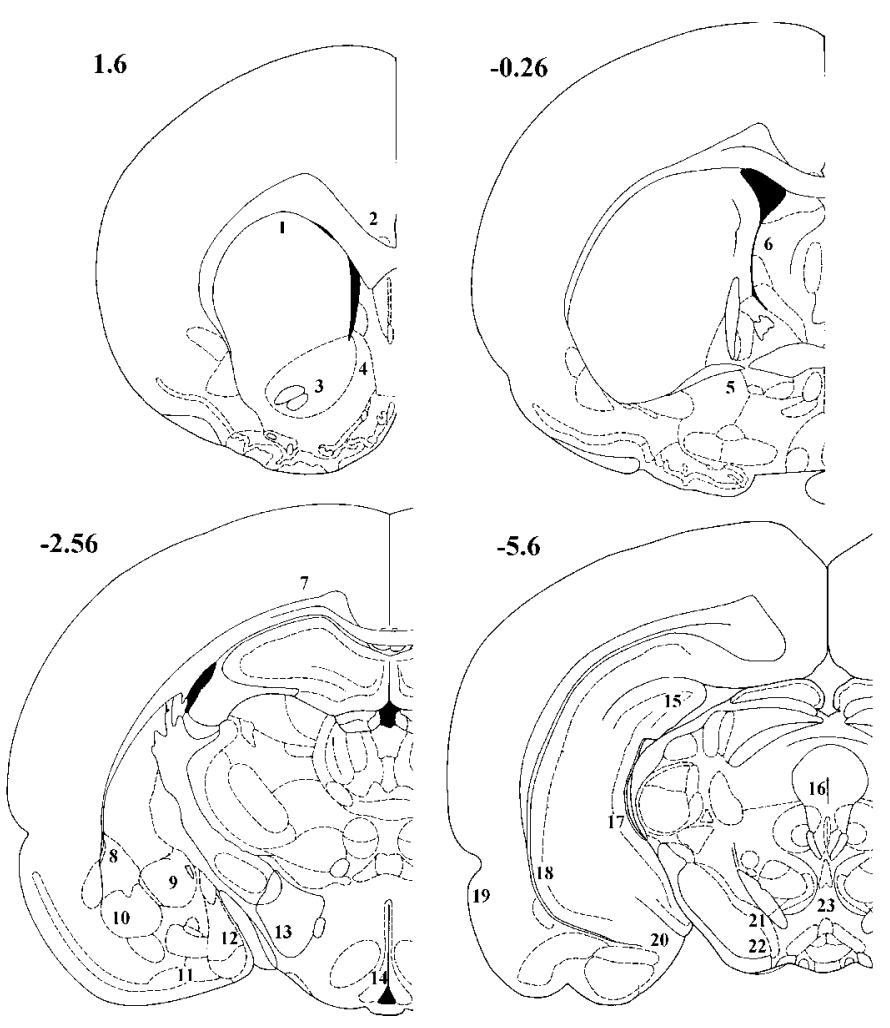

Figure 3. Schematic representation of regions analyzed. Numbers at the top left of each section represent the distance (in millimeters) from bregma. Numbers in the sections represent the regions (area in square millimeters) analyzed as follows: 1 , dorsal caudate putamen, $0.135 ; 2$, anterior cingulate, $0.135 ; 3$, NAc core, $0.135 ; 4$, NAc shell, $0.1 ; 5$, ventral pallidum, 0.09; 6 , lateral septal nucleus, $0.09 ; 7$, motor cortex, $0.125 ; 8$, lateral amygdala, 0.09; 9, central amygdala, 0.134; 10, basolateral amygdala, 0.134; 11, cortical amygdala, 0.09; 12, medial amygdala, 0.09; 13, lateral hypothalamus, $0.09 ; 14$, arcuate nucleus, $0.05 ; 15$, dentate gyrus, $0.1 ; 16$, central gray area, $0.07 ; 17$, hippocampal CA3 region, $0.1 ; 18$, hippocampal CA1 region, 19 , entorhinal cortex, $0.125 ; 20$, ventral subiculum, $0.1 ; 21$, substantia nigra pars compacta, $0.6 ; 22$, substantia nigra pars reticulata, 0.07; 23, VTA, 0.07. Drawings were adapted from the Paxinos and Watson atlas (1986).

regardless of whether they were exposed to the environment only or to the environment and priming injections.

Exposure to the cocaine self-administration environment enhanced Fos protein expression (Fig. 6), evident from a main effect of conditioning group in the NAc core $\left(F_{(2,29)}=4.53 ; p<0.05\right)$, NAc shell $\left(F_{(2,29)}=4.05 ; p<0.05\right), \operatorname{BlA}\left(F_{(2,29)}=5.58 ; p<0.01\right)$, dentate gyrus $\left(F_{(2,29)}=3.23 ; p<0.05\right)$, hippocampal CA1 region $\left(F_{(2,29)}=3.20 ; p<0.05\right)$, and anterior cingulate $\left(F_{(2,29)}=4.29\right.$; $p<0.05)$ (Figure 7). In all of these regions, the no extinction group exhibited significantly more Fos-positive nuclei than both the control and extinction groups (Fisher's LSD test; $p<0.05$ ), and there were no significant differences between the latter two groups. Also in the central gray area, post hoc analysis of a one-way ANOVA with each group as a separate level $\left(F_{(5,34)}=\right.$ 3.73; $p<0.01)$ indicated that, within the groups exposed to the cocaine self-administration environment only, the no extinction group exhibited significantly more Fos-positive nuclei than both the control and extinction groups (Fisher's LSD test; $p<0.05$ ), and there were no significant differences between the latter two groups. However, planned comparisons indicated no significant difference between the no extinction-no lever group and either the extinction or no extinction groups in the central gray area and

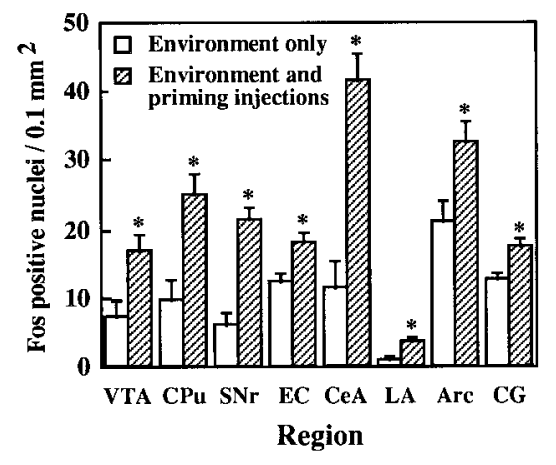

Figure 4. Fos-positive nuclei/ $0.1 \mathrm{~mm}^{2}( \pm \mathrm{SEM})$ in brain regions that exhibited enhanced Fos protein expression by the priming injections. The data are collapsed across conditioning groups. ${ }^{*} p<0.05$, represents a difference from the respective group receiving exposure to the environment only; Fisher's LSD test. Cpu, Caudate putamen; EC, entorhinal cortex; $C e A$, central amygdala; $L A$, lateral amygdala; $A r c$, arcuate nucleus; $C G$, central gray area.

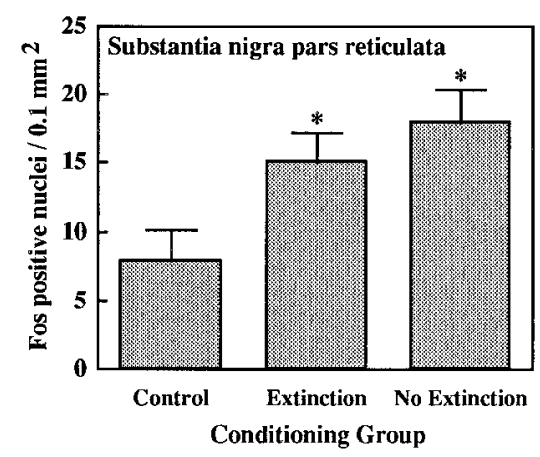

Figure 5. Fos-positive nuclei/ $0.1 \mathrm{~mm}^{2}( \pm \mathrm{SEM})$ in the substantia nigra pars reticulata demonstrating enhanced Fos protein expression in rats with a history of cocaine self-administration. The data are collapsed across groups receiving exposure to the environment versus the environment and priming injections. ${ }^{*} p<0.05$, represents a difference from controls; Fisher's LSD test.

NAc core, suggesting that some of the Fos protein expression in the no extinction group may have been caused by the act of lever pressing. In contrast, planned comparisons indicated a significant difference between the extinction and the no extinction-no lever groups in the NAc shell $\left(t_{(17)}=2.20 ; p<0.05\right), \mathrm{BlA}\left(t_{(17)}=1.71\right.$; $p<0.055)$, dentate gyrus $\left(t_{(17)}=2.02 ; p<0.05\right)$, and hippocampal CA1 region $\left(t_{(17)}=2.09 ; p<0.05\right)$ but no significant difference between the no extinction group and the no extinction-no lever group. These findings suggest that the increase in Fos protein expression in the no extinction group in these regions was not simply caused by lever pressing behavior. Furthermore, this pattern of changes across groups is consistent with a conditioned enhancement of Fos protein expression elicited by the selfadministration environment.

In the anterior cingulate, there was conditioned enhancement of Fos protein expression, as well as enhancement by the priming injections, but only in animals with a history of cocaine selfadministration (Fig. 7). A one-way ANOVA performed with each group as a separate level that indicated a significant main effect of group $\left(F_{(5,34)}=2.99 ; p<0.05\right)$. Within the groups receiving exposure to the environment only, Fos protein expression was greater in the no extinction group relative to both the controls and extinction groups, consistent with conditioned Fos protein 


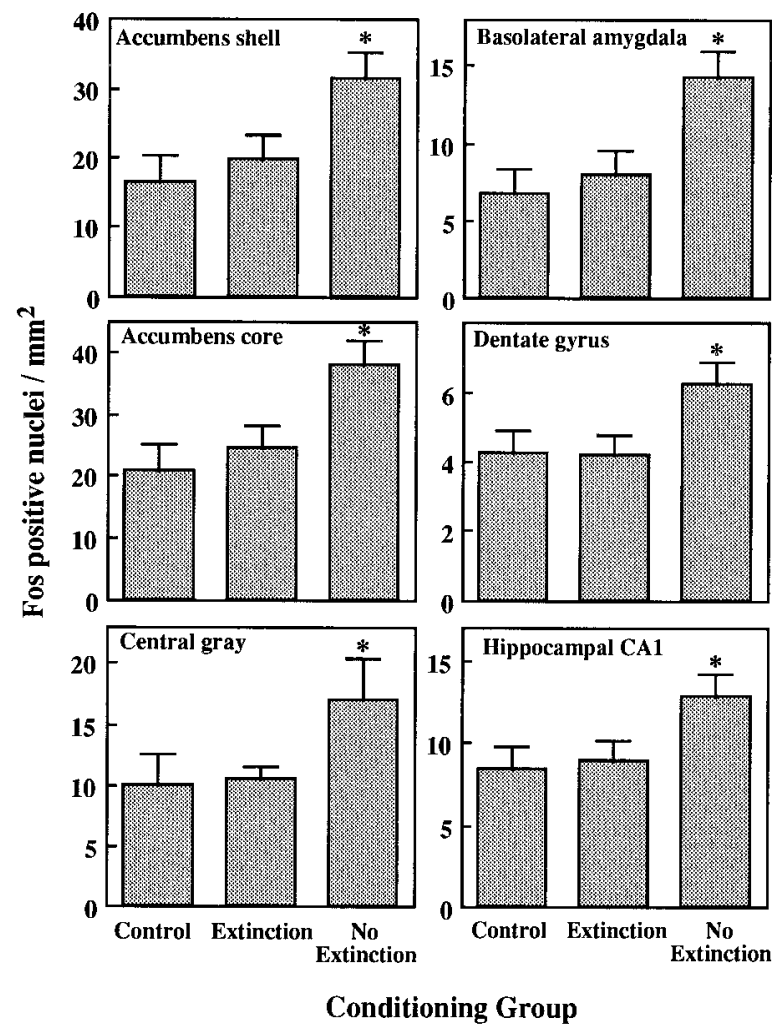

Figure 6. Fos-positive nuclei $/ 0.1 \mathrm{~mm}^{2}( \pm \mathrm{SEM})$ in brain regions that exhibited a pattern of changes consistent with conditioned Fos protein expression by the self-administration environment. The data are collapsed across groups receiving exposure to the environment versus the environment and priming injections, except in the central gray area, which illustrates the groups receiving exposure to the environment only. ${ }^{*} p<$ 0.05 , represents a difference from all other groups; Fisher's LSD test.

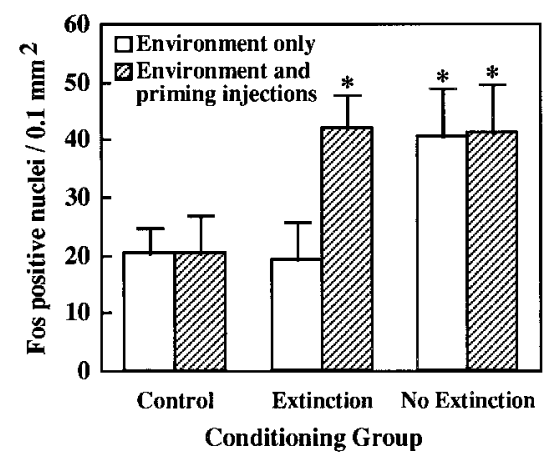

Figure 7. Fos-positive nuclei $/ 0.1 \mathrm{~mm}^{2}( \pm \mathrm{SEM})$ in the anterior cingulate. ${ }^{*} p<0.05$, represents a significant difference from other groups shown; Fisher's LSD test.

expression described above. Furthermore, planned comparisons indicated a marginally significant difference between the extinction and the no extinction-no lever groups $\left(t_{(11)}=1.73 ; p<\right.$ $0.056)$ but no significant difference between the no extinction group and the no extinction-no lever group, suggesting that the increase in Fos protein expression in the no extinction group was not simply caused by lever pressing behavior. Within the groups receiving the priming injections, Fos protein expression was greater in both the extinction and no extinction groups relative to the control group (Fisher's LSD test; $p<0.05$ ). It should also be noted that, within the no extinction groups, there was no difference between the group exposed to the environment only versus the group exposed to the environment and priming injections, suggesting that exposure to either the environment or the priming injections produced a maximal increase in Fos protein expression.

There were no significant group differences in Fos protein expression in the ventral pallidum, substantia nigra pars compacta, motor cortex, lateral septal nucleus, lateral hypothalamus, medial amygdala, cortical amygdala, hippocampal CA3 region, or ventral subiculum, although there was a trend toward a significant conditioning group effect in the latter region $\left(F_{(2,29)}\right.$ $=2.99 ; p<0.07)$.

\section{DISCUSSION}

Extinction training abolished cocaine-seeking behavior elicited by the self-administration environment, because responding in animals with a history of cocaine self-administration declined to saline-yoked control levels by day 11 of extinction training (Fig. 1). This finding suggests that extinction training decreased the incentive salience of the self-administration environment. The cocaine priming injection reinstated responding in all groups initially, but maintained responding throughout the cocaine reinstatement test phase only in animals with a history of cocaine self-administration that did not undergo extinction training (no extinction group). Extinction training attenuated reinstatement of cocaine-seeking behavior by the cocaine primer because animals with a history of cocaine self-administration and extinction training (extinction group) exhibited an intermediate level of responding after the cocaine priming injection that did not differ from the controls or the no extinction groups (Fig. 2). The finding that responding was less robust in the extinction group relative to the no extinction group during this test phase suggests that some of the reinstatement of responding in the no extinction group may have been attributable to cocaine-induced recovery of incentive motivational effects of the environmental stimuli. Thus, the cocaine priming injection may reinstate incentive motivational effects of the self-administration environment.

Regarding possible neural substrates of these behavioral effects, four different patterns of Fos protein expression were observed. First, the priming injections enhanced Fos protein expression, regardless of conditioning group in the VTA, caudate putamen, SNr, entorhinal cortex, central amygdala, lateral amygdala, arcuate nucleus, and central gray area (Fig. 4). The magnitude of Fos protein expression did not differ across conditioning groups, suggesting that the effect was likely caused by unconditioned effects of cocaine or stress associated with the injection procedure. Because many of these regions are innervated by dopamine neurons, Fos protein expression in these regions may be caused by increased dopamine receptor stimulation. In any case, it is unclear whether these changes are involved in cocaineseeking behavior because the effects were observed in the control and extinction groups.

A second distinct pattern of Fos protein expression occurred in the $\mathrm{SNr}$. In addition to the effect of priming injections mentioned above, there was also an effect of conditioning group, indicating that animals with a history of cocaine self-administration exhibited enhanced Fos protein expression relative to controls, regardless of whether they received extinction training (Fig. 5). This effect is not likely related to cocaine-seeking behavior because it was observed in the extinction group exposed to the environment only that did not engage in cocaine-seeking behavior. Thus, the 
effect likely reflects enhanced reactivity resulting from cocaine experience and/or cocaine withdrawal.

A third pattern of Fos protein expression consistent with conditioned enhancement by the cocaine self-administration environment was observed in the NAc core, NAc shell, BlA, hippocampal CA1 region, dentate gyrus, and central gray area (Fig. 6 ). In all of these regions, enhanced Fos protein expression was observed in the no extinction group relative to controls and extinction groups, regardless of whether the animals received priming injections. This pattern of changes in Fos protein expression corresponds to the pattern of cocaine-seeking behavior in these groups, suggesting that these regions play some role in the behavior. Furthermore, Fos protein expression in the no extinction-no lever group was significantly higher than the extinction group, but not different from the no extinction group, in the anterior cingulate, NAc shell, BlA, hippocampal CA1 region, and dentate gyrus. This suggests that enhanced Fos protein expression in these regions was not caused by lever pressing per se.

A fourth distinct pattern of Fos protein expression was observed in the anterior cingulate in which, in addition to conditioned enhancement by the self-administration environment, there was also enhancement by the priming injections but only in groups with a history of cocaine self-administration (Fig. 7). Thus, all groups exhibiting cocaine-seeking behavior on the test day also exhibited enhanced Fos protein expression in the anterior cingulate. The magnitude of the enhanced Fos protein expression was similar in the no extinction groups, regardless of priming injections, and was also similar in groups receiving the priming injections, regardless of extinction training; this suggests that a maximal effect on Fos protein expression occurred after exposure to either type of stimuli. Importantly, enhanced Fos protein expression in the anterior cingulate by the priming injections was not likely caused by stress associated with the injection procedure because it was not observed in the controls given priming injections. Furthermore, this effect was not simply caused by lever pressing because the no extinction-no lever group also exhibited enhanced Fos protein expression relative to the extinction group.

The changes in Fos protein expression in the anterior cingulate, NAc shell, BlA, hippocampal CA1 region, and dentate gyrus described above suggest that these regions likely play a role in cocaine-seeking behavior elicited by the self-administration environment apart from the act of lever pressing. Indeed, these brain regions have been implicated in various functions (e.g., motivation, emotion, memory, attention, and expectancy) (for review, see Aggleton, 1992; Kalivas and Barnes, 1993; Devinsky et al., 1995; Schultz, 1998) that contribute to cocaine-seeking behavior. Furthermore, previous research offers converging lines of evidence to support the hypothesis that the amygdala and anterior cingulate are involved in the incentive motivational effects of cocaine-paired stimuli. For instance, cocaine-paired stimuli elicit conditioned locomotion and conditioned place preference, as well as enhanced Fos protein expression in the anterior cingulate and amygdala in rats (Brown et al., 1992; Crawford et al., 1995). Furthermore, imaging studies in human cocaine abusers have demonstrated that cocaine-paired stimuli increase self-reports of cocaine craving and metabolic activity in the anterior cingulate and amygdala (Grant et al., 1996; Maas et al., 1998; Childress et al., 1999). It is unlikely that these effects are attributable to performance of a particular behavior or to cognitive processes involved in response-contingent procurement of drug because these factors vary across studies. Common to all of these studies, however, are incentive motivational effects of cocaine-paired stimuli, as reflected by cocaine-seeking behavior, cocaineconditioned place preference, and cocaine craving. Furthermore, previous research suggests that the BlA is necessary for the ability of cocaine-paired stimuli to reinstate cocaine-seeking behavior or to serve as cocaine-conditioned secondary reinforcers (Whitelaw et al., 1996; Meil and See, 1997).

The lack of a change in Fos protein expression in some of the brain regions examined must be interpreted with caution because it does not preclude the possibility that these regions are involved in cocaine-seeking behavior. Furthermore, the present study failed to observe changes in Fos protein expression by cocaine and cocaine-paired stimuli that have been observed previously. For instance, previous studies examining Fos protein expression by cocaine-paired stimuli have found enhanced Fos protein expression in the lateral septal nucleus but have not found changes in the NAc or hippocampus (Brown et al., 1992; Crawford et al., 1995). Furthermore, previous studies have reported increased Fos protein expression in the NAc after acute cocaine administration that exhibits tolerance after repeated administration (Graybiel et al., 1990; Brown et al., 1992; Hope et al., 1992; Moratalla et al., 1996). These discrepancies may be attributable to differences in previous cocaine experience, cocaine challenge dose, amount of handling, length of drug-free period before testing, and/or anatomical subregion analyzed.

The overall pattern of Fos protein expression was different in animals exhibiting cocaine-seeking behavior elicited by the selfadministration environment versus priming injections, suggesting that these stimuli activate different neural substrates. Based on this finding, we hypothesize that different neural circuits may be involved in the incentive motivational effects of these stimuli for cocaine. Importantly, this hypothesis is contrary to some of the leading theories of incentive motivation for drug that suggest the same mechanisms are involved for both types of stimuli (Stewart, 1983; Robinson and Berridge, 1993). We further hypothesize that a limbic circuitry is involved in incentive motivation for cocaine elicited by cocaine-paired stimuli. Moreover, the anterior cingulate may be part of a final common pathway for cocaine-seeking behavior elicited by cocaine-paired stimuli and priming injections given that Fos protein expression in this region was associated with cocaine-seeking behavior elicited by either type of stimuli. Further research using procedures that directly manipulate these brain regions is needed to examine these hypotheses. This line of research is important because understanding the neural mechanisms involved in incentive motivation for cocaine has implications for developing and evaluating treatments for cocaine dependence.

\section{REFERENCES}

Aggleton JP (1992) The amygdala (Aggleton JP, ed). New York: Wiley-Liss.

Bradberry CW, Rubino SR (1998) Neurotransmitter release during cocaine self-administration and cues in rhesus monkeys. Natl Inst Drug Abuse Res Monogr 179:87.

Brown EE, Robertson GS, Fibiger HC (1992) Evidence for conditional neuronal activation following exposure to a cocaine-paired environment: role of forebrain limbic structures. J Neurosci 12:4112-4121.

Carroll ME, France CP, Meisch RA (1981) Intravenous selfadministration of etonitazene, cocaine, and phencyclidine in rats during food deprivation and satiation. J Pharmacol Exp Ther 217:241-247.

Childress A, Ehrman R, McLellan A, O’Brien C (1988) Update on behavioral treatments for substance abuse. Natl Inst Drug Abuse Res Monogr 90:183-192.

Childress AR, Mozley PD, McElgin W, Fitzgerald J, Reivich M, O’Brien 
CP (1999) Limbic activation during cue-induced cocaine craving. Am J Psychiatry 156:11-18.

Crawford CA, McDougall SA, Bolanos CA, Hall S, Berger SP (1995) The effects of the kappa agonist U-50,488 on cocaine-induced conditioned and unconditioned behavior and Fos immunoreactivity. Psychopharmacology 120:392-399.

de la Garza R, Johanson CE (1987) The effects of food deprivation on the self-administration of psychoactive drugs. Drug Alcohol Depend 19:17-27.

Devinsky O, Morrell MJ, Vogt BA (1995) Contributions of the anterior cingulate cortex to behaviour. Brain 118:279-306.

Di Ciano P, Blaha CD, Phillips AG (1998) Conditioned changes in dopamine oxidation currents in the nucleus accumbens of rats by stimuli paired with self-administration or yoked-administration of D-amphetamine. Eur J Neurosci 10:1121-1127.

Fuchs RA, Tran-Nguyen LTL, Specio SE, Groff RS, Neisewander JL (1998) Predictive validity of the extinction/reinstatement model of drug craving. Psychopharmacology 135:151-160.

Grant S, London ED, Newlin DB, Villemagne VL, Liu X, Contoreggi C, Phillips RL, Kimes AS, Margolin A (1996) Activation of memory circuits during cue-elicited cocaine craving. Proc Natl Acad Sci USA 93:12040-12045.

Gratton A, Wise RA (1994) Drug- and behavior-associated changes in dopamine-related electrochemical signals during intravenous cocaine self-administration in rats. J Neurosci 14:4130-4146.

Graybiel AM, Moratalla R, Robertson HA (1990) Amphetamine and cocaine induce drug-specific activation of the c-fos gene in striosomematrix compartments and limbic subdivisions of the striatum. Proc Natl Acad Sci USA 87:6912-6916.

Herrera DG, Robertson HA (1996) Activation of c-fos in the brain. Prog Neurobiol 50:83-107.

Hope B, Kosofsky B, Hyman SE, Nestler EJ (1992) Regulation of immediate early gene expression and AP-1 binding in the rat nucleus accumbens by chronic cocaine. Proc Natl Acad Sci USA 89:5764-5768.

Kalivas PK, Barnes CD (1993) Limbic motor circuits and neuropsychiatry (Kalivas PK, Barnes CD, eds). Boca Raton: CRC.

Kiyatkin EA, Stein EA (1994) Biphasic changes in mesolimbic dopamine signal during cocaine self-administration. NeuroReport 5:1005-1008.

Maas LC, Lukas SE, Kaufman MJ, Weiss RD, Daniels SL, Rogers VW, Kukes TJ, Renshaw PF (1998) Functional magnetic resonance imaging of human brain activation during cue-induced cocaine craving. Am J Psychiatry 155:124-126.

Markou A, Weiss F, Gold LH, Caine SB, Schulteis G, Koob GF (1993) Animal models of drug craving. Psychopharmacolology 112:163-182.
Meil WM, See RE (1997) Lesions of the basolateral amygdala abolish the ability of drug associated cues to reinstate responding during withdrawal from self-administered cocaine. Behav Brain Res 87:139-148.

Moratalla R, Elibol B, Vallejo M, Graybiel AM (1996) Network-level changes in expression of inducible Fos-Jun proteins in the striatum during chronic cocaine treatment and withdrawal. Neuron 17:147-156.

Neisewander JL, O'Dell LE, Tran-Nguyen LTL, Castaneda E, Fuchs RA (1996) Dopamine overflow in the nucleus accumbens during extinction and reinstatement of cocaine self-administration behavior. Neuropsychopharmacology 15:506-514.

Paxinos G, Watson LC (1986) The rat brain in stereotaxic coordinates. New York: Academic.

Robinson TE, Berridge KC (1993) The neural basis of drug craving: an incentive-sensitization theory of addiction. Brain Res Rev 20:247-291.

Schultz W (1998) Predictive reward signal of dopamine neurons. J Neurophysiol 80:1-27.

Self DW, Barnhart WJ, Lehman DA, Nestler EJ (1996) Opposite modulation of cocaine-seeking behavior by $\mathrm{D}_{1^{-}}$and $\mathrm{D}_{2}$-like dopamine receptor agonists. Science 271:1586-1589.

Sharp FR, Sagar SM, Swanson RA (1993) Metabolic mapping with cellular resolution: c-fos vs. 2-deoxyglucose. Crit Rev Neurobiol $7: 205-228$.

Stewart J (1983) Conditioned and unconditioned drug effects in relapse to opiate and stimulant drug self-administration. Prog Neuropsychopharmacol Biol Psychiat 7:591-597.

Stewart J (1984) Reinstatement of heroin and cocaine selfadministration behavior in the rat by intracerebral application of morphine in the ventral tegmental area. Pharmacol Biochem Behav 20:917-923.

Tran-Nguyen LTL, Fuchs RA, Coffey GP, Baker DA, O’Dell LE, Neisewander JL (1998) Dopamine overflow in the amygdala during withdrawal from self-administered cocaine. Neuropsychopharmacology 19:48-59.

Weissenborn R, Deroche V, Koob GF, Weiss F (1996) Effects of dopamine agonists and antagonists on cocaine-induced operant responding for a cocaine-associated stimulus. Psychopharmacology 126:311-322.

Whitelaw RB, Markou A, Robbins TW, Everitt BJ (1996) Excitotoxic lesions of the basolateral amygdala impair the acquisition of cocaineseeking behavior under a second-order schedule of reinforcement. Psychopharmacology 127:213-224.

Young ST, Porrino LJT, Porrino LJ, Iadarola MJ (1991) Cocaine induces striatal c-fos-immunoreactivity proteins via dopaminergic D1 receptors. Proc Natl Acad Sci USA 88:1291-1295. 